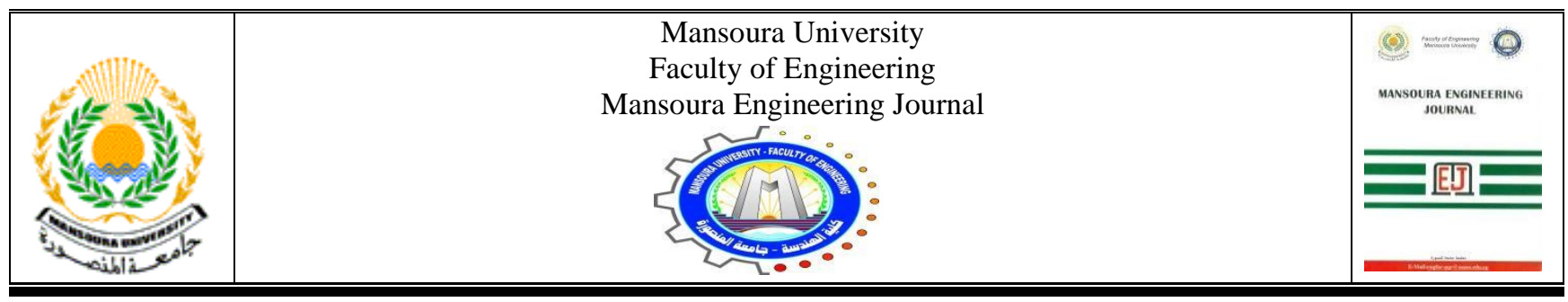

\title{
Enhancing the performance of smart grid using Model Predictive Control
}

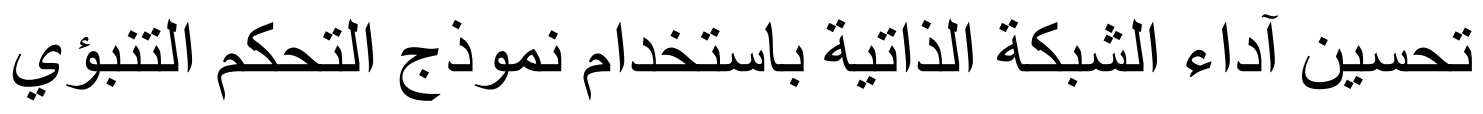

Yara A.Sultan, Sahar S. Kaddah and Mostafa A. Elhosseini

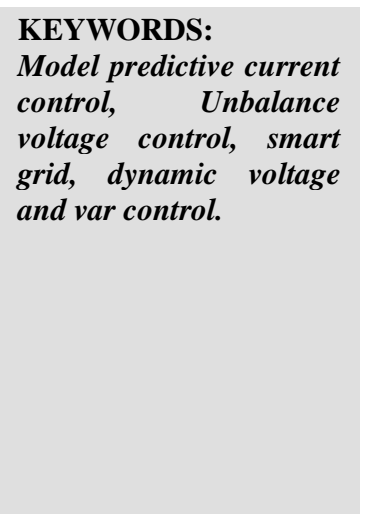

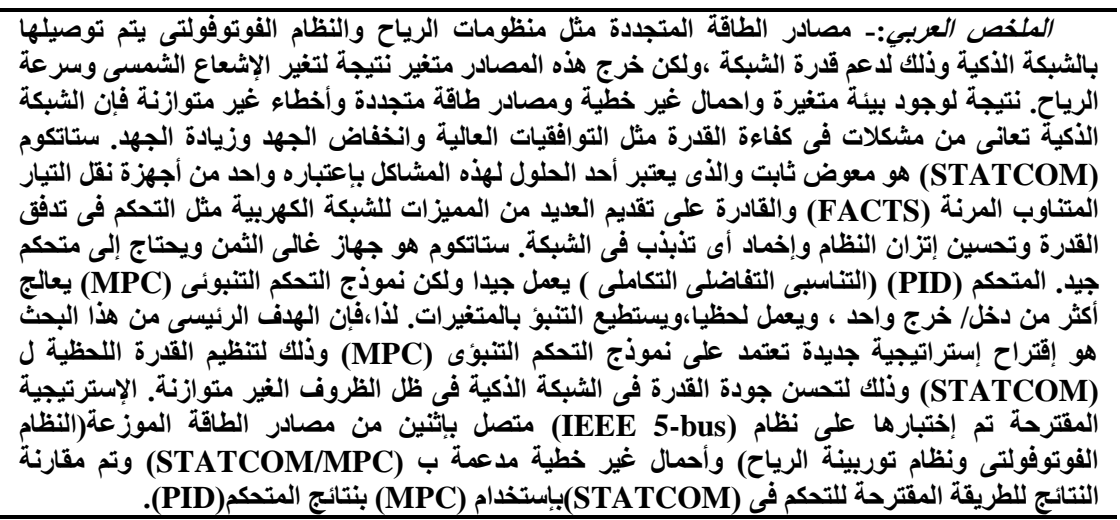

\begin{abstract}
Renewable energy sources such as wind energy conversion systems and photovoltaic systems are connected to the smart grid to promote the grid power. However, the output of those sources changes due to the sunlight and wind speed variations. Owing to the existence of dynamic environment, nonlinear loads, renewable energy resources, and unbalanced faults, smart grids suffer from power quality problems such as high harmonic contents, voltage sag, and voltage swell. STATCOM is a static compensator which considered as one solution to these problems as one of the flexible alternating current transmission system (FACTS) devices that are able to provide several advantages to the
\end{abstract}

Received: 28 December, 2016 - revised: 14 February, 2017 accepted: 26 February, 2017

Yara A. Sultan, is with the Department of Electrical Engineering, Mansoura University,Egypt (e-mail: yaraabdalla2@gmail.com).

Sahar S. Kaddah, is with the Department of Electrical Engineering, Mansoura University,Egypt (email: skaddah@mans.edu.eg)

Mostafa A. Elhosseini, is with the Department of Computer engineering \&Control Systems,, Mansoura University, Egypt (email: melhosseini@gmail.com) power grid such as controlling the power flow, enhancing system stability, and suppressing any oscillation in the grid. On the other hand, STATCOM is expensive device and needs a good controller. A proportional-integral-derivative (PID) controller works well but model predictive control (MPC) handles more than one input/output, works on real-time basis and is able to predict variables. So, the main contribution of this paper is proposing a control strategy based on MPC to regulate the instantaneous power of STATCOM to improve the power quality in the smart grid under unbalanced conditions. The proposed strategy is tested on IEEE 5-bus system connected with two distributed energy systems (photovoltaic system and wind turbine system), and nonlinear loads supported by a STATCOM/MPC and the digital simulation results using the proposed STATCOM controlled by MPC are compared with the PID controller results.

\section{INTRODUCTION}

$\mathrm{S}$ MART grid is considered as smart electrical power grids that can respond to adopt with any events occur in the system. Smart grid contains a variety of energy and operational measurements such as 


\section{E: 2 YARA A.SULTAN, SAHAR S. KADDAH AND MOSTAFA A. ELHOSSEINI}

smart appliances, renewable energy resources, smart meters, and energy efficiency resources [1]. Smart grid has a robust control system that can work automatically to govern the behavior of the grid and enhance system stability and reliability. Smart grid allows higher renewable energy resources penetration, can deal with climate change, dynamic loads, and it is able to reduce greenhouse gas emission [2].

Since smart grid has lots of variabilities, dynamic components, nonlinear loads, distributed generator (DG) sources with variable output and subject to different types of loads. So, such a grid with fluctuating power and poor power quality may damage the component of the grid and overheat system components. FACTS devices are able to provide several advantages to the transmission system such as (1) Transmission capacity enhancement, (2) power flow control, (3) Transient stability improvement, (4) Power oscillation damping, and (5) Voltage stability and control.

A rapidly operating FACTS device such as STATCOM can compensate continuously both active/reactive power in order to control dynamic swings and improve the system performance under various system conditions. If the STATCOM used in smart grid is equipped with a very efficient and fast controller, the system will work efficiently under different fluctuating conditions.

Previous control strategy applied in this case has shown that these methods suffer from: (1) complicated control strategy (2) an additional control is needed for controlling positive and negative sequence under unbalanced condition, (3) existence of harmonics, (4) dependent performance on controllers' parameter sensitivity, and (5) having time delay which causes an error with dynamic behavior system[3].

This paper proposes a Model Predictive Control strategy to control STATCOM in the smart grid distribution system with nonlinear loads, two DGs sources and subject to unbalanced faults. The MPC controller strategy objectives are:

Controlling STATCOM to inject/ absorb reactive power to the grid according to grid needs taking into consideration its constraints.

Dealing with all grid imbalance voltage issues with fast and flexible dynamic behavior.

Overcoming the challenge of operating DGs in a power system.

Adjusting STATCOM before changing the output set point and taking action smoother and closer to optimal value.

The performance of the system is measured by different power quality indices such as total harmonic distortion of current (THDi), total harmonic distortion of voltage (THDv), voltage sag and voltage swell. All these indices are compared with the performance of PID at the same condition.

The rest of the paper is organized as follows: section 2 covers background and related work, problem formulation will be discussed in Section 3. However, section 4 presents the proposed algorithm followed by simulation results in Section 5. Finally, the conclusion will be drawn in section 6 .

\section{BACKGROUND AND RELATED WORK}

STATCOM is a static synchronous generator operated as static compensator connected in parallel with the smart grid near DG, its output current (Capacitive or Inductive) can be controlled independently of the AC system voltage. The STATCOM, shown in Figure 1, has a charged capacitor as a direct current source that feeds an DC/AC power converter with high switching frequency (IGBT) that produces a set of outputs with controllable three phase voltages [4].



Figure 1: Main circuit of a three phase STATCOM

In order to stabilize the STATCOM to compensate grid voltage under unbalanced grid conditions, different control strategies were proposed by scholars' worldwide.

$\mathrm{Xu}$ and Cartwright [5] applied a direct power control (DPC) to get a better dynamic response with DGs. The presented method has a variable switching frequency with a more complex power filter. Space vector modulation was implemented by $\mathrm{Xu}$ et al. [6] to modify DPC strategies and obtain constant switch frequency but the control system was complicated.

Eloy-Garcia et al. [7] proposed a vector control based DPC strategy with needed positive and negative decomposition for voltage and current. Therefore, additional controllers are required to control both positive and negative sequences which made the control more complex. A PI controller was used for the current controller as proposed by Li et al [8]. Despite that, under unbalanced voltage condition, PI Controller was not able to suppress the harmonics.

Guan and $\mathrm{Xu}$ [9] applied dual current controller where two groups of PI current vector controller were used for positive and negative components, it degraded system dynamic response and stability owing to the delay and errors introduced by the current decomposition process. Zeng and Chang [10] proposed VSC control based on a combination between space vector modulation (SVM) and predictive control which provides constant switching 
frequency. However, this system had some issues related to the parameter sensitivity and control delays.

The idea behind MPC is easy to understand since it can handle safety Constraints, and can handle more than one input / output (MIMO-systems). Additionally, MPC can receive a real-time feedback with faster response than regular control. The control strategy proposed adjusts the real and reactive power in the smart grid containing DGs. The MPC receives instantaneous feedback from the bus voltages and bus currents in the smart grid. Moreover, it dynamically assigns set point of the STATCOM [11]. MPC predicts the value of the current and voltage generated from these variant DGs for a few seconds ahead and reduces the effects of voltage variation in the system.

Karamanakos et al. [12] proposed a finite control set model predictive control (FCS-MPC) strategy on Cascaded H-Bridge (CHB) converter which is one of the most popular topologies of STATCOM. However, it suffers from huge computation burden. Mariethoz et al. [13] applied the explicit MPC which is an approximate optimization approach where parts of the optimization task can be pre- calculated offline. However, this control strategy is not appropriate for a nonlinear system.

A hybrid MPC which is a combination between FCSMPC and PWM technique is presented for 19-level cascaded H-bridge STATCOM by Ramirez et al. [14].The MPC block is used to control the switches in the H-bridge, but this model is suboptimal approach because it did not take the redundant voltage vectors across three phases into consideration.

This paper proposed a fast MPC control for STATACOM .The main contribution of this paper is that MPC can be used online with a low-cost processor with reduced computational time for MPC in STATCOM.

IEEE-Five bus system connected with two DGs (wind turbine and photovoltaic system), non-linear loads and compensator device (STATCOM) controlled by MPC are used to enhance the performance of the system. The implementation is done using MATLAB $\backslash$ SIMULINK version 2013 [15] shown in Figure 2 and Figure 3.

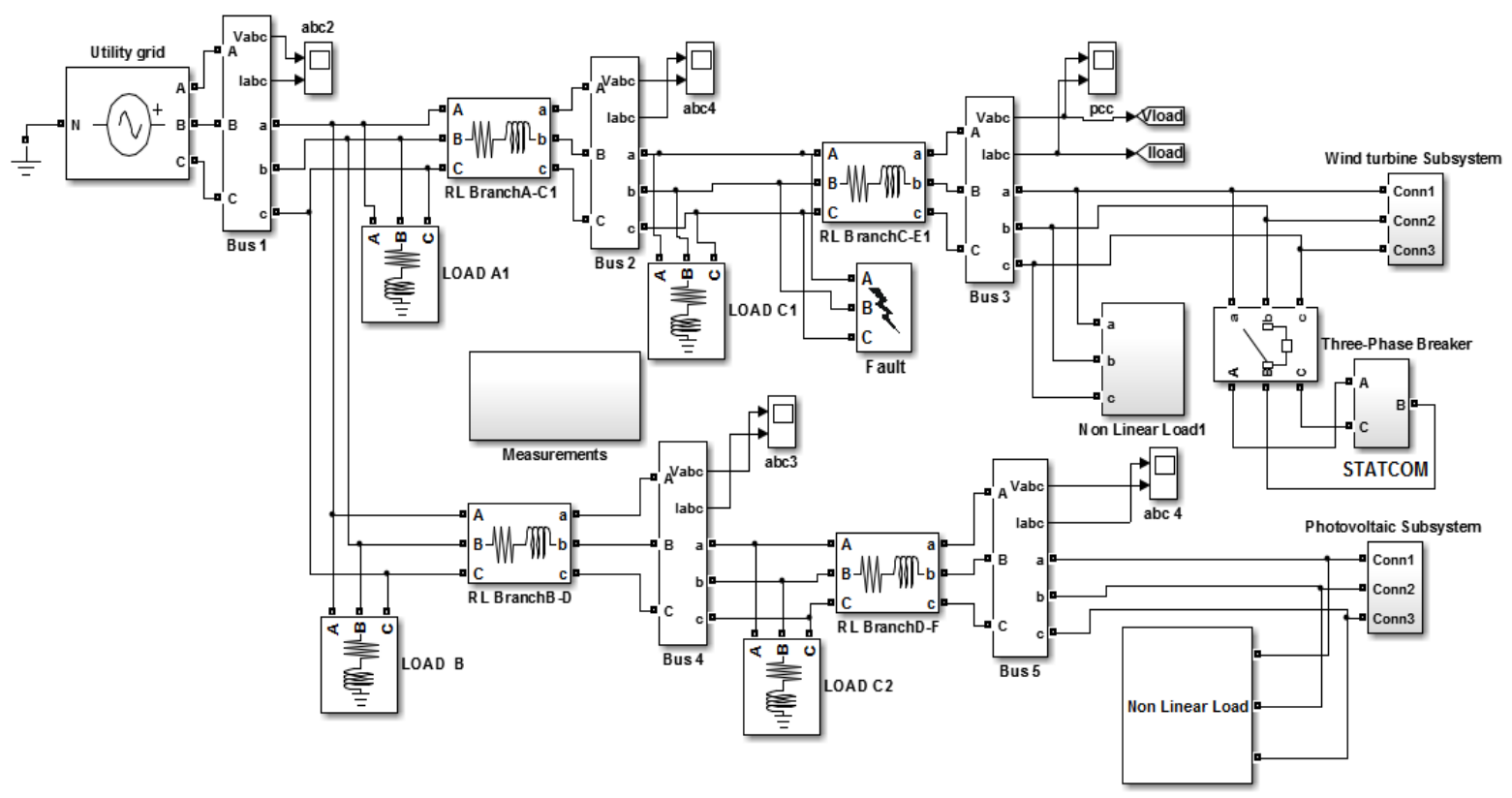

Figure 2: IEEE five bus system connected with DG'S and MPC model

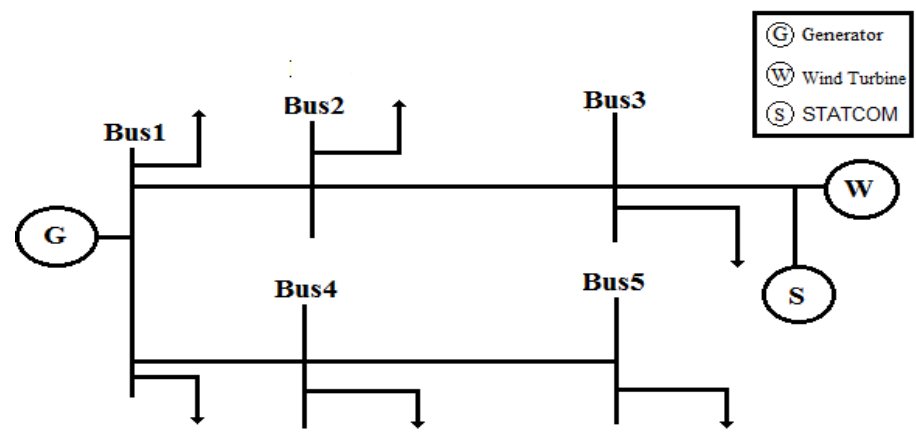

Figure 3: Single line diagram for IEEE-5 bus system 


\section{Problem Formulation}

The switching states of the STATCOM are determined by the gating signals $S_{a}, S_{b}, S_{c}[16]$ as follows:

$S_{a}=\left\{\begin{array}{ll}1, & \text { if } S_{1} \text { on and } S_{4} \text { off } \\ 0, & \text { if } S_{1} \text { off and } S_{4} \text { on }\end{array}\right\}$

$S_{b}=\left\{\begin{array}{ll}1, & \text { if } S_{3} \text { on and } S_{6} \text { off } \\ 0, & \text { if } S_{3} \text { off and } S_{6} \text { on }\end{array}\right\}$

$S_{c}=\left\{\begin{array}{ll}1, & \text { if } S_{5} \text { on and } S_{2} \text { off } \\ 0, & \text { if } S_{5} \text { off and } S_{2} \text { on }\end{array}\right\}$

Where, the output Voltage $e_{x n}(\mathrm{x}=\mathrm{a}, \mathrm{b}, \mathrm{c})$ of the STATCOM are calculated by the switching function of $S_{x}(x=a, b, c)$, which can be derived as

$e_{a n}=S_{a} u_{d c}$

$e_{b n}=S_{b} u_{d c}$

$e_{c n}=S_{c} u_{d c}$

Under unbalanced voltage condition, the current has two components positive sequence and negative sequence, so the reference current $i_{\alpha, r e f}, i_{\beta, \text { ref }}$ can be calculated as summation of positive and negative sequence components

$i_{\alpha, r e f}=i_{\alpha, r e f}^{p}+i_{\alpha, r e f}^{n}$

$i_{\beta, r e f}=i_{\beta, r e f}^{p}+i_{\beta, r e f}^{n}$

According to the mathematical model, the reference current is a function of AC-side voltage. So it is determined as follows [17]

$\left[\begin{array}{l}i_{\alpha, r e f}^{p} \\ i_{\beta, r e f}^{p}\end{array}\right]=\left[\begin{array}{cc}m & n \\ -n & m\end{array}\right]\left[\begin{array}{l}e_{\alpha}^{p} \\ e_{\beta}^{p}\end{array}\right]$

$\left[\begin{array}{l}i_{\alpha, \text { ref }}^{n} \\ i_{\beta, \text { ref }}^{n}\end{array}\right]=\left[\begin{array}{cc}m & n \\ -n & m\end{array}\right]\left[\begin{array}{l}e_{\alpha}^{n} \\ e_{\beta}^{n}\end{array}\right]$

Where,

$$
\begin{aligned}
& \mathrm{m}=\frac{2 P_{\text {av,ref }}}{3\left[\left(e_{\alpha}^{p}\right)^{2}+\left(e_{\beta}^{p}\right)^{2}-\left(e_{\alpha}^{n}\right)^{2}-\left(e_{\beta}^{n}\right)^{2}\right]} \\
& \mathrm{n}=\left(1-\sqrt{1-4(\omega L m)^{2}} /(2 \omega L)\right.
\end{aligned}
$$

And $\omega=2 \pi f, \mathrm{f}=50 \mathrm{HZ}$

According to Equations (9) and (10), the reference of the current has two sequences components under unbalanced voltage condition. The first part is related to the coefficient $\mathrm{m}$, where $\mathrm{m}$ is a function of the DC-side active power injected by the three-phase STATCOM. By controlling this part, a stable active power in AC-side can be obtained while voltage ripple is eliminated. The second part is the coefficient $\mathrm{n}$, where $\mathrm{n}$ is a function of the ACside inductance which represents the disturbance component for AC-side power. The influence of the inductance of the AC-side on the power of the AC-side can be suppressed by manipulating this part.

Model Predictive Control is used to control STATCOM with rapid and dynamic performance suitable with the electrical grid behavior. MPC used as current controller of inner loop for STATCOM control scheme, with high performance and no static error under unbalanced voltage condition.
The MPC predicts in every sampling time interval the grid side current in order to achieve the optimum reference current according to the historical data of the grid. Then MPC determines the optimum switch states of the STATCOM-IGBT satisfying the current and voltage limits. The grid side current at next instant in MPC can be obtained from the following equations

$$
\begin{aligned}
& i_{\alpha}(k+1)= \\
& \left(1-\frac{R T_{s}}{L}\right) i_{\propto}(k)+\frac{T_{s}}{L}\left[e_{\propto}(k)-\right. \\
& \left.u_{\propto}(K)\right] \\
& i_{\beta}(k+1)=\left(1-\frac{R T_{s}}{L}\right) i_{\beta}(k)+\frac{T_{s}}{L}\left[e_{\beta}(k)-u_{\beta}(K)\right]
\end{aligned}
$$

Where, $T_{s}$ is the sampling period of controller. $u_{\propto}, u_{\beta}$ can be expressed as a function of the switch states and the voltage of the DC-side at the instant of $\mathrm{k} T_{s}$ as follows

$u_{\propto}(k)=$

$\frac{2}{3} u_{d c}(k)\left[S_{a}(k)-\frac{1}{2} S_{b}(k)-\right.$

$\left.\frac{1}{2} S_{c}(k)\right]$

$u_{\beta}(k)=\frac{\sqrt{3}}{3} u_{d c}(k)\left[S_{b}(k)-S_{c}(k)\right]$

Where, $u_{d c}(k)$ is the DC-side voltage of STATCOM at instant $\mathrm{k}$.

The MPC evaluates the predictive value of grid side current $\left(i_{\alpha}(k+2), i_{\beta}(k+2)\right)$ in each instant under each switch state taking cost function( $g$ )into consideration. Then MPC chooses the switch state that minimizing the cost function $(g)$ at the $\operatorname{instant}\left((k+1) T_{s}\right)$. The MPC repeats the above procedure until it minimizes the following cost function $g$

$g=\left|i_{\alpha, r e f}(k+2)-i_{\alpha}(k+2)\right|+\mid i_{\beta, r e f}(k+2)-i_{\beta}(k+$ 2)|

PI controller is used to control the DC-side voltage of STATCOM. So the reference value of the instantaneous active power of STATCOM at the AC-side is

$$
\begin{aligned}
& P_{g, r e f}= \\
& {\left[\left(K_{p}+\right.\right.} \\
& \left.\frac{K_{i}}{s}\right)\left(u_{d c, r e f}-\right. \\
& \left.\left.u_{d c}\right)\right] \cdot u_{d c, r e f}
\end{aligned}
$$

\section{MPC ALGORITHM}

In the industry, most of the controllers are mainly PID due to its cheap price and ease of tuning. PID controller solves well most of the mono-variable control tasks. However, in more complex systems related to multiconstraints, the PID controller doesn't always give satisfactory results and difficult to maintain.

Model predictive control [18] is a technique that focuses on constructing controllers that can adjust the control action before any change actually occurs in the output set-point. The MPC consists of an optimization problem at each time 
instants, K. The MPC optimizer computes a new control input vector, $U_{k}$, to be fed to the system taking the constraints into consideration as shown in Figure 4



Figure 4: System controlled by MPC block diagram

An MPC Algorithm consists of Cost function, constraints, and a model of the process which describes the inputs /outputs behavior of the process. The model of the system in each current and voltage constraints is assumed in discrete state space model of the following general form.

$x(k+1)=A x(k)+B u(k)$

$y(k)=C x(k)+D u(k)$

Where $x(k)$ state vector at time $k, y(k)$ output vector, $u(k)$ vector of inputs, A state transition matrix ,B input coefficient matrix , C output coefficient matrix , and D direct path coefficient matrix.

MPC control works based on a receding horizon policy that means the internal model predicts plant behavior over a future horizon in time.

Plant interactions or time delays are captured by the model. Constraints on plant inputs / outputs are explicitly handled. Feedback compensates for modeling error and rejects disturbances. A new control sequence is executed when a new measurements are available.

MPC solves the optimization problem in control sequences at each time step as shown in Figure 5. The optimization problem depends on the objective function. The optimization problem proposed in this paper is mixed integer programming (MIQP) [19].

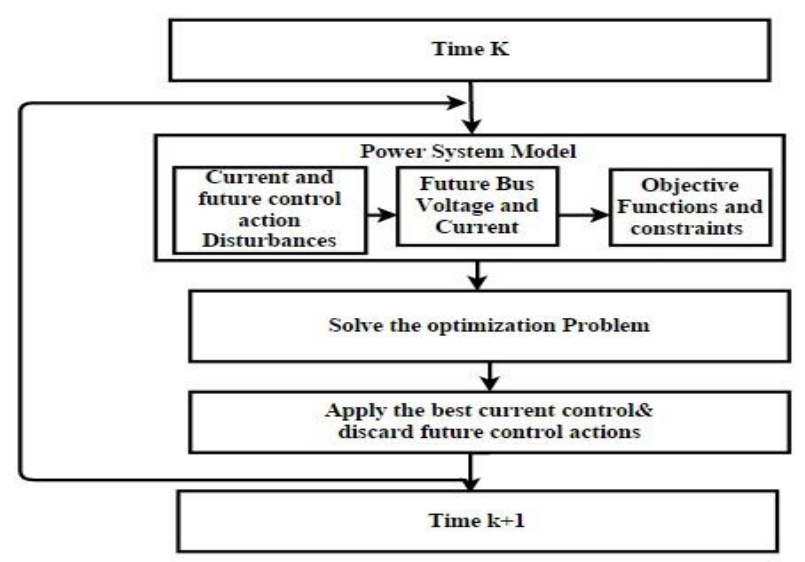

Figure 5: MPC strategy operation sequence

\section{SIMULATION RESULTS}

To verify the effectiveness of the proposed strategy, the following steps are considered:

Step1: Model the smart grid with its load, DGs, STATCOM controlled by MPC as a bench mark system.

Step 2: Measure the performance of smart grid at normal condition.

Step 3: Apply any types of faults at Bus 2 near to loads and STATCOM.

Step 4: Measure the performance and evaluate all power quality indices in this case at all buses.

Step 5: Repeat steps 3 and 4 but with PID controller instead of MPC at the same condition.

Step 6: Compare MPC performance with PID performance at the same condition to verify the flexibility and reliability of the MPC over PID. 


\section{5-1 Performance indices}

Power quality disturbances is any deviations occur in voltage or current waveform from its ideal waveforms. The Power Quality Indices [20] is characterized by different indices such as the total harmonic distortion factor [21], Voltage sag, Voltage Swell, and Voltage Fluctuation.

\section{5-2 Fault disturbance results}

The proposed control is applied on the smart grid described in Figure 2. In this study, a double phase to ground fault occurs close to the wind turbine bus with a fault transition time between [0.2-0.4] sec. while the ground resistance $R_{g}$ equals 0.001 and the control transition time is set at $0.3 \mathrm{sec}$. Voltage, current, active power, and reactive power are monitored at (Fault bus, and Wind Turbine Bus). Then the power quality indices are calculated using MPC and PID Controllers, separately.

\section{5-2-1 Voltage and current measurement at Fault bus}

The waveforms of voltage and current at the fault bus are monitored using PID and MPC as shown in Figure 6 and 7
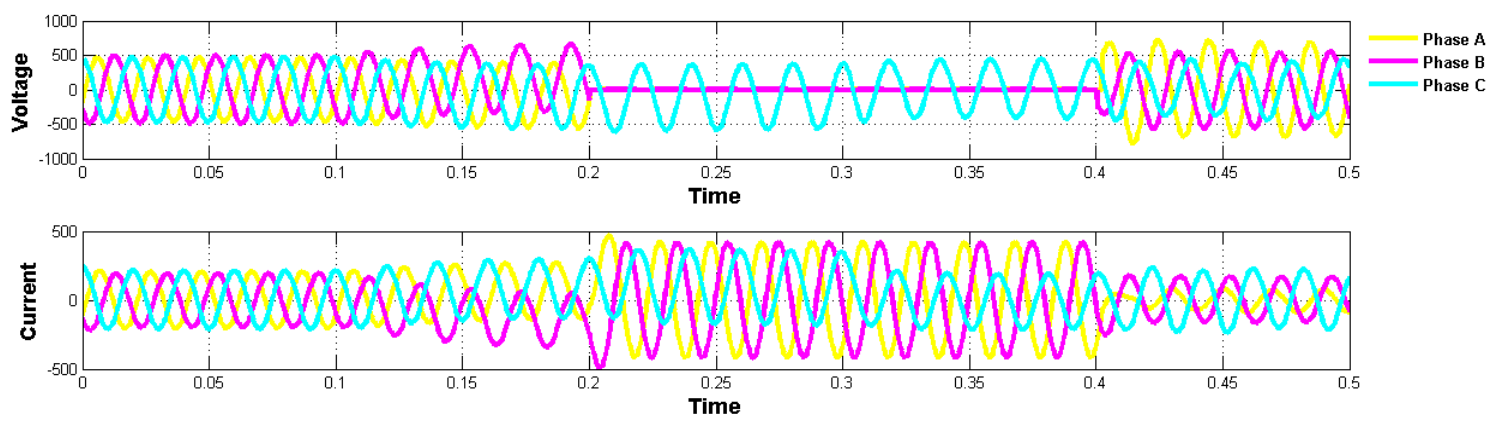

Figure 6: Voltage and current measurement at Fault Bus using PID control Strategy
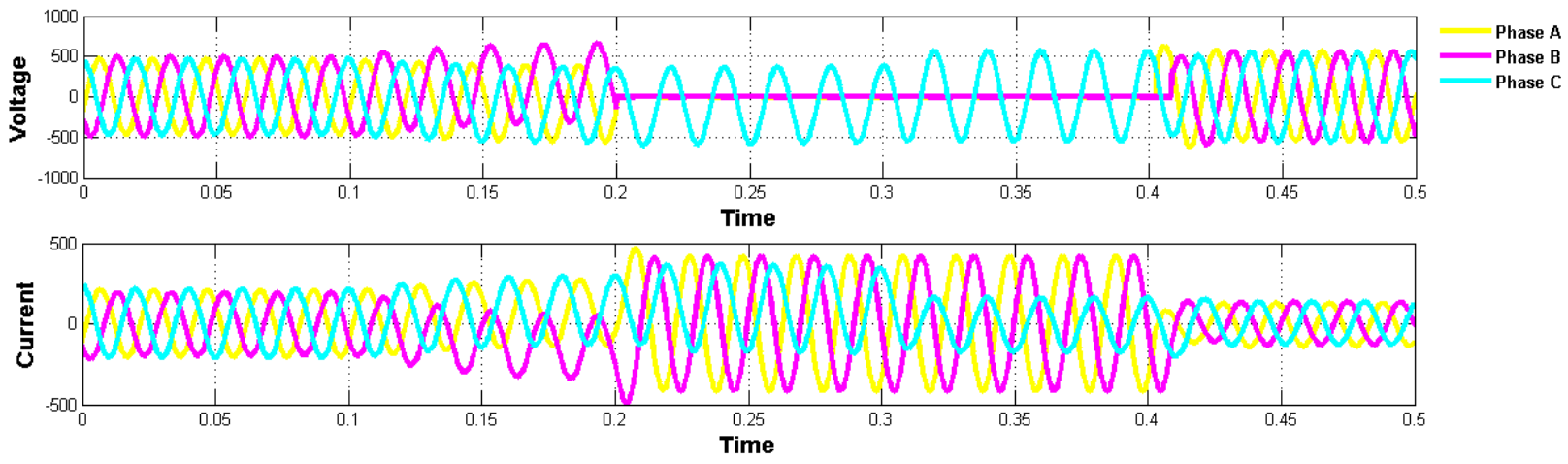

Figure 7: Voltage and current measurement at Fault Bus using MPC control Strategy

As depicted from Figure 6 and Figure 7, the PID controller fails to restore system stability. However, the MPC controller satisfies voltage and current stability.

The THDv and THDi for both controllers are calculated and listed in Table 1. It is evident from this table that the MPC has a better impact in the voltage and current than the PID controller. Additionally, the MPC decreases THD in voltage and current.

TABLE 1

THD IN VOLTAGE AND CURRENT USING PID AND MPC CONTROLLER AT

\begin{tabular}{l||l||l||l||l}
\multicolumn{1}{l||}{ Controller } & PID & MPC \\
\hline Distortion & THDv & THDi & THDv & THDi \\
\hline Phase A & 0.01379 & 0.0324 & 0.00635 & 0.00381 \\
\hline Phase B & 0.01545 & 0.02379 & 0.00630 & 0.00369 \\
\hline Phase C & 0.03869 & 0.02901 & 0.00634 & 0.00386
\end{tabular}

From Table 1, it is observed that MPC controller improves the system stability and decreases the THD in voltage and current. Furthermore, the MPC makes the voltage and current symmetrical

\subsubsection{Wind turbine bus}

Wind turbine bus is classified as the most fluctuation bus so it is important to study in details the behavior of the system after fault occur at this bus and controller connected to the grid.

a) Voltage and current at wind turbine bus

The waveforms of voltage and current at the winding bus using PID and MPC are shown in Figure 8 and 9 


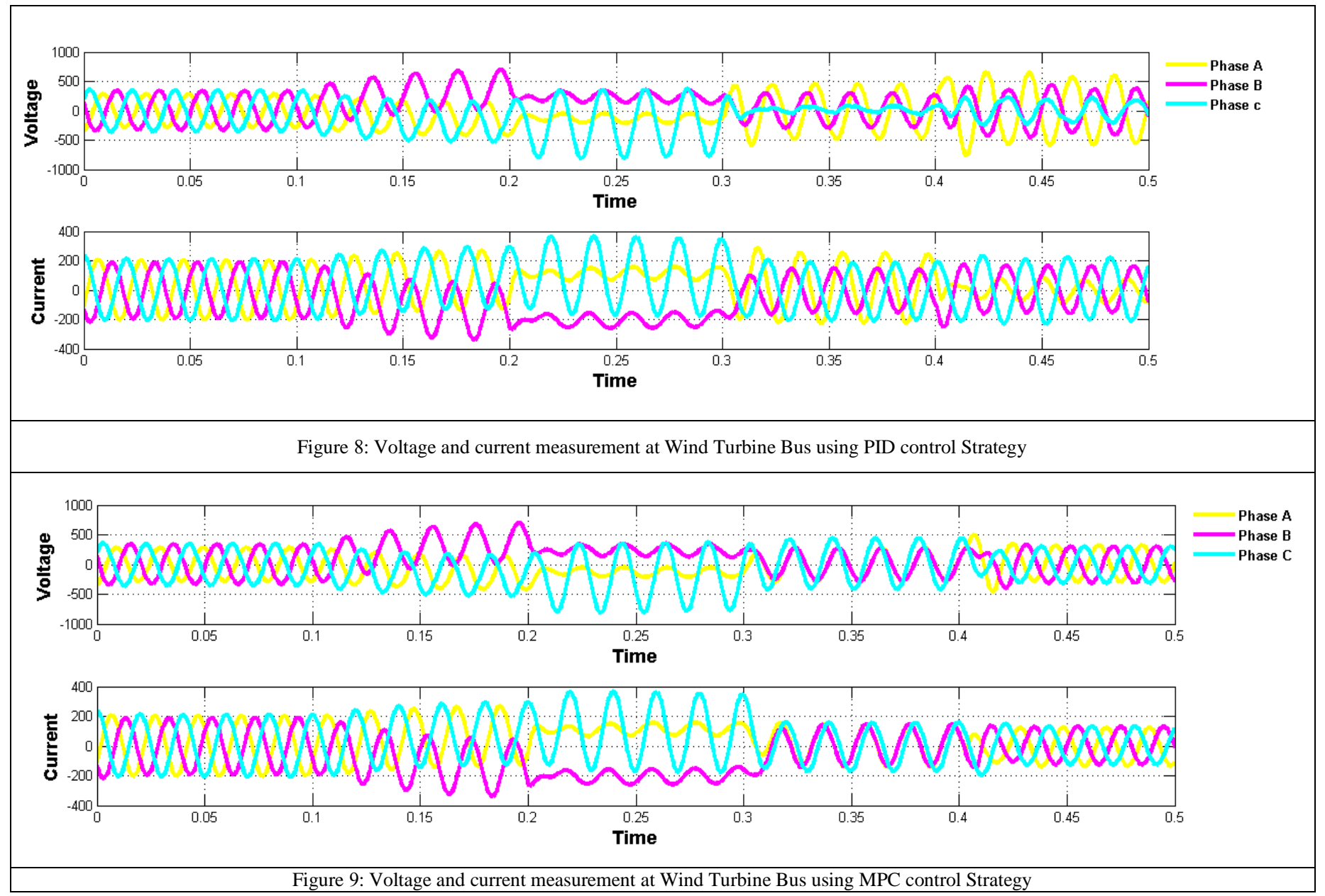

From Figures 8 and 9, it may be seen that the MPC has a better impact in voltage and current than the PID. The THD is measured at wind turbine bus using both controllers as shown in Table 2.

TABLE 2

THD IN VOLTAGE AND CURRENT USING PID AND MPC CONTROLLER AT WIND TURBINE BUS

\begin{tabular}{l||l||l||l||l}
\multicolumn{1}{l||}{ Controller } & PID & MPC & \multicolumn{1}{l}{} \\
\hline Distortion & THDv & THDi & THDv & THDi \\
\hline Phase A & 0.0326 & 0.03411 & 0.02193 & 0.00396 \\
\hline Phase B & 0.04373 & 0.02493 & 0.02174 & 0.00383 \\
\hline Phase C & 0.1745 & 0.0299 & 0.02191 & 0.00401
\end{tabular}

As shown from Table 2, the MPC decreases the THD in current and voltage and waveforms become balanced.

\section{b) Active power at wind turbine bus}

The active power at wind turbine bus calculated by MPC and PID controllers is shown in Figure 10. It is revealed from this figure that the MPC makes the active power smoother than the PID controller.

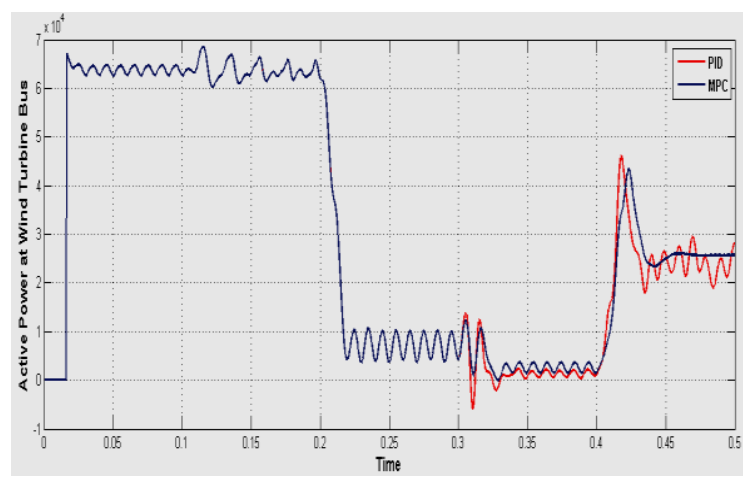

Figure 10: Active Power measurement at Wind Turbine Bus using PID -MPC control Strategy

\section{c) Reactive power at wind turbine bus}

Reactive power at wind turbine bus that is injected / absorbed by STATCOM to get voltage balanced at its desired value is shown in Figure 11. It is evident from this figure that MPC can eliminate the distortion in reactive power wave while the PID fails to do so. 


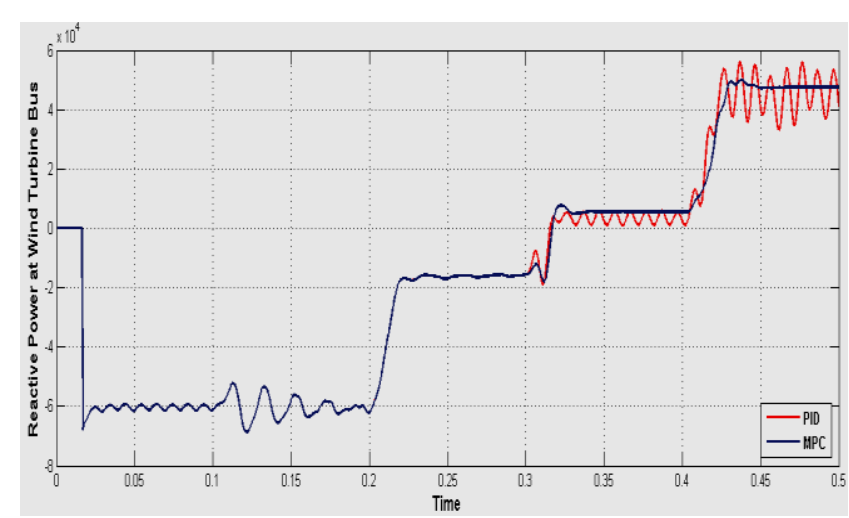

Figure 11: Reactive Power measurement at Wind Turbine Bus using PID MPC control Strategy

d) Analysis of the behavior of grid at wind turbine bus

Table 3 shows the behavior of the three phases of voltage at wind turbine bus before the fault occurs in the grid from time $(0-0.2)$ sec.
TABLE 3

BEHAVIOR OF VOLTAGE FROM TIME (0-0.2SEC) AT WIND TURBINE BUS

\begin{tabular}{|c|c|c|}
\hline Phase & $(0-0.1) \mathrm{sec}$ & $(0.1-0.2) \mathrm{sec}$ \\
\hline $\mathbf{A}$ & $\begin{array}{l}\text { Voltage fluctuation due to } \\
\text { Nonlinear loads }\end{array}$ & Voltage sag in Phase $A=0.5 \mathrm{pu}$ \\
\hline $\mathbf{B}$ & $\begin{array}{l}\text { Voltage fluctuation due to } \\
\text { Nonlinear loads }\end{array}$ & $\begin{array}{l}\text { Instantaneous voltage swell in } \\
\text { Phase } B=0.84 \mathrm{pu}\end{array}$ \\
\hline $\mathrm{C}$ & $\begin{array}{l}\text { Voltage fluctuation due to } \\
\text { Nonlinear loads }\end{array}$ & $\begin{array}{l}\text { Voltage sag in Phase } \mathrm{C}= \\
0.5 \mathrm{pu}\end{array}$ \\
\hline
\end{tabular}

As shown in Table 3 that at period $(0-0.2)$, there is a fluctuation in voltage due to nonlinear loads and DG's. At $0.2 \mathrm{sec}$, a double phase to ground fault occurs at phase A and $\mathrm{B}$. This causes voltage sag in $\mathrm{A}, \mathrm{B}$ and $\mathrm{C}$.

Table. 4 shows the behavior of voltage when the controller is connected with the grid at period $(0.3-0.5 \mathrm{sec})$.

As shown in Table. 4 that at $0.3 \mathrm{sec}$ when a controller connected with the grid, PID controller makes three phase unbalanced when MPC make phase A, B balanced with the same voltage sag $=0.28$. At $0.4 \mathrm{sec}$

PID fails to restore the system stability but MPC is able to stabilize the system.

TABLE 4

Voltage Sag/Swell at Wind Turbine Bus for Double Line to Ground Fault

\begin{tabular}{l||l||l||l||l|l} 
Time Period & $(0.2-0.3) \mathrm{sec}$ & $(0.3-0.4) \mathrm{sec}$ & $(0.4-0.5) \mathrm{sec}$ & MPC \\
\hline $\begin{array}{l}\text { With/without } \\
\text { controller }\end{array}$ & without & PID & MPC & PID & \\
\hline Voltage sag(pu) & 0.6 (phase A) & 0.8 (phase C) & 0.28 (phase A\&B) & 0.4 (phase C) & NO \\
\hline Voltage swell(pu) & NO & 0.8 (phase A) & 0.8 (phase C) & 1.2 (phase A) & NO
\end{tabular}

\subsection{Parameter sensitivity}

MPC is affected by four parameters [22] that are used to tune MPC for better performance and to assess robustness under model mismatch

1. Control interval sets the elapsed time between successive adjustments of the controller's manipulated variables.

2. Prediction horizon is the numbers of samples in the future that MPC controller predicts the plant output.

3. Control horizon is the number of samples within the prediction horizon where the MPC controller can affect the control action

4. Weight tuning adjusts individual weightson manipulated variables rates, manipulated variable, and output variables.

Taking these parameters into consideration and tuning their values in the model, the results of (voltage and current waveforms) give the same results shown in figure 7 and 9, which mean that MPC is not affected by horizons or weight tuning and MPC gets a good performance without tuning parameters at every interval.

MPC is more efficient than the proposed techniques in [12], [13], and [14] as it predicts the best voltage vector, then it selects the best switch state that minimizes the cost function (g). So, MPC decreases the computational burden.
Furthermore, it is suitable for nonlinear systems and gives an accurate optimization approach because all optimization tasks are calculated online in the run time. Moreover, the proposed method gives an accurate optimal solution as it takes the redundant voltage vectors across the three phases, $\left(e_{a}, e_{b}, e_{c}\right)$, of STATCOM into consideration.

\section{CONCLUSION}

This paper presented a control strategy using MPC to enhance the performance and improve the power quality of the smart grid containing a large amount of DGs by controlling the STATCOM. The performance of smart grid was measured under double line to ground fault and at different buses (WT bus, grid bus, fault bus, etc...). The smart grid power quality is measured in terms of total harmonic distortion in voltage and current, voltage balance, voltage sag, voltage swell, and smoothness of both active and reactive power. The proposed control strategy was applied to an STATCOM connected to a smart grid consists of IEEE 5-bus connected with wind turbine and photovoltaic array, this system was implemented in MatLab/ Simulink environment. The effectiveness of the proposed strategy was proved by comparing the corresponding results when using PID controller instead of MPC. The 
simulation result showed that MPC was able to decrease THD in voltage by $0.25 \mathrm{PU}$ compared to PID .and THD in current by 0.28PU compared to PID. Also, it helped in keeping the symmetry of voltage and current waveform during disturbances and also damped oscillation and smoothened both active and reactive power at wind turbine bus (the most fluctuating bus).

\section{REFERENCES}

[1] F. Liet al., "Smart Transmission Grid: Vision and Framework," in IEEE Transactions on Smart Grid, vol. 1, no. 2, pp. 168-177, Sept. 2010.

[2] Y.Zhang and X.Meng, "Research on operation evaluation technology system of smart distribution grid," Power Engineering and Automation Conference (PEAM), 2011 IEEE, Wuhan, 2011, pp. 542-546.

[3] K.Yang, X.oxiao Cheng, Y.Wang, L.Chen and G.Chen, "PCC voltage stabilization by D-STATCOM with direct grid voltage control strategy," Industrial Electronics (ISIE), 2012 IEEE International Symposium on, Hangzhou, 2012, pp. 442-446.

[4] M. Vimalraj, B. Alex and M. Tamilarasi, "StatCom control for voltage stability improvement at a fixed speed wind farm under unbalanced faults," Information Communication and Embedded Systems (ICICES), 2014 International Conference on, Chennai, 2014, pp. 1-6.

[5] Lie $\mathrm{Xu}$ and P. Cartwright, "Direct active and reactive power control of DFIG for wind energy generation," in IEEE Transactions on Energy Conversion, vol. 21, no. 3, pp. 750-758, Sept. 2006.

[6] [6] L. Xu, D. Zhi and L. Yao, "Direct Power Control of Grid Connected Voltage Source Converters," Power Engineering Society General Meeting, 2007. IEEE, Tampa, FL, 2007, pp. 1-6.

[7] J. Eloy-Garcia, S. Arnaltes and J. L. Rodriguez Amenedo, "Extended direct power control of a three-level Neutral Point Clamped Voltage Source Inverter with unbalanced voltages," Power Electronics Specialists Conference, 2008. PESC 2008. IEEE, Rhodes, 2008, pp. 3396-3400.

[8] S. Li, T. A. Haskew and L. Xu, "Control of HVDC Light System Using Conventional and Direct Current Vector Control Approaches," in IEEE Transactions on Power Electronics, vol. 25, no. 12 , pp. 3106-3118, Dec. 2010.

[9] M. Guan and Z. Xu, "Modeling and Control of a Modular Multilevel Converter-Based HVDC System Under Unbalanced Grid Conditions," in IEEE Transactions on Power Electronics, vol. 27, no. 12, pp. 4858-4867, Dec. 2012.
[10] Q. Zeng and L. Chang, "An Advanced SVPWM-Based Predictive Current Controller for Three-Phase Inverters in Distributed Generation Systems," in IEEE Transactions on Industrial Electronics, vol. 55, no. 3, pp. 1235-1246, March 2008.

[11] J. Rodriguez, and P. Cortes, Predictive Control of Power Converters and Electrical Drives, pp. 31-39: John Wiley \& Sons, Ltd, 2012.

[12] P. Karamanakos, K. Pavlou, and S. Manias, "An Enumeration Based Model Predictive Control Strategy for the Cascaded HBridge Multilevel Rectifier," IEEE Trans. Ind. Electron., vol. 61, no. 7, pp. 3480-3489, Jul. 2014.

[13] S. Mariethoz, A. Domahidi, and M. Morari, "High-Bandwidth Explicit Model Predictive Control of Electrical Drives," IEEE. Trans. Ind. Appl., vol. 48, no. 6, pp. 1980-1992, Nov-Dec, 2012.

[14] R. O. Ramirez, J. R. Espinoza, F. Villarroel, E. Maurelia, and M. E. Reyes, "A Novel Hybrid Finite Control Set Model Predictive Control Scheme With Reduced Switching," IEEE Trans. Ind. Electron., vol. 61, no. 11, pp. 5912-5920, Nov, 2014.

[15] MATLAB, Optimization and Control Tool box, www.mathworks.com.

[16] J.Han, Z.Ma and D.Peng, "Analysis of Model Predictive Current Control for Voltage Source Inverter," in Research Journal of Applied Sciences, Engineering and Technology 6(21): 3986-3992, Nov 2013.

[17] Z.Zhou, C.Xia, X.Gu, Q.Geng and W. Chen, "Model predictive control of three-phase Voltage Source Rectifiers under unbalanced grid voltage conditions," Power Electronics, Machines and Drives (PEMD 2014), 7th IET International Conference on, Manchester, 2014, pp. 1-6.

[18] Y.Wang and S. Boyd, "Fast Model Predictive Control Using Online Optimization," in IEEE Transactions on Control Systems Technology, vol. 18, no. 2, pp. 267-278, March 2010.

[19] A. Richards and J. How, "Mixed-integer programming for control," American Control Conference, 2005. Proceedings of the 2005, 2005, pp. 2676-2683 vol. 4.

[20] P.Caramia, G.Carpinelli, P.Verde, "Power Quality Indices in Liberalized Markets," 2009.

[21] R. Muralekrishnen and P. Sivakumar, "Improving the power quality performance for distributed power generation," Computing, Electronics and Electrical Technologies (ICCEET), 2012 International Conference on, Kumaracoil, 2012, pp. 203-211.

[22] A. Bemporad, N. L. Ricker and J. G. Owen, "Model predictive control - new tools for design and evaluation," American Control Conference, 2004. Proceedings of the 2004, Boston, MA, USA, 2004,

pp. $5622-5627$ 